\title{
MODELING OF REFLECTED CRACKS IN ASPHALT CONCRETE PAVEMENT OF HIGHWAYS
}

\section{Aleksey Kamenchukov}

Pacific National University, Institute of Architecture and Civil Engineering,

Khabarovsk, Russian

Federation

\section{Nikolay Kim}

Pacific National University, Institute of Architecture and Civil Engineering,

Khabarovsk, Russian

Federation

\section{Ilya Ukrainskiy}

Pacific National University, Institute of Architecture and Civil Engineering,

Khabarovsk, Russian Federation

\author{
Nikina Bushuev \\ Pacific National University, \\ Institute of Architecture and \\ Civil Engineering, \\ Khabarovsk, Russian \\ Federationv
}

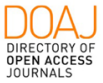

Crossref
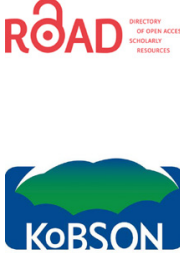

Key words: highway, reflected cracks, operational state, coating quality, defects, strength assessment, stress-strain state

Cite article:

Aleksey, K., Ilya, U., Nikina, B., \& Nikolay, K. [2021]. Modeling of reflected cracks in asphalt concrete pavement of highways. Journal of Applied Engineering Science, 19(2) 466 - 474. DOI:10.5937/jaes0-29136

Online aceess of full paper is available at: www.engineeringscience.rs/browse-issues 


\title{
MODELING OF REFLECTED CRACKS IN ASPHALT CONCRETE PAVEMENT OF HIGHWAYS
}

\author{
Aleksey Kamenchukov*, llya Ukrainskiy, Nikina Bushuev, Nikolay Kim \\ Pacific National University, Institute of Architecture and Civil Engineering, Khabarovsk, Russian Federation
}

The paper considers the issues of crack resistance of multilayer systems made of asphalt concrete, namely: the causes and features of the occurrence and development of "reflected" cracks are investigated. A study of the operational state of highways was carried out and the prerequisites for the formation of defects on the pavement were determined, including the regional features of the work of the road structure. The authors comprehensively studied the causes of internal and external defects and deformations of asphalt concrete pavements. The most popular technologies for sealing cracks and restoring the pavement are considered, the experience of repairing roads in the western part of Russia, Europe and the USA is also investigated. The results of determining the rate of formation and development of defects in the surface of the exploited roads are presented. In laboratory conditions, work was carried out to simulate cracks in two-layer samples of fine-grained asphalt concrete. Test specimens with a height and diameter of $10 \mathrm{~cm}$ were made by molding and compacted in layers, a crack was laid in the lower layer of the specimen. After gaining strength, the samples were tested for compression. Analysis of the results of physical modeling made it possible to put forward an assumption about the existence of a relationship between the presence (absence) of internal defects in the coating and the strength of the structure. To confirm the hypothesis, mathematical modeling of the operation of a two-layer system in the GenIDE32 software package was performed. Evaluation of the stressstrain state by the finite element method showed the presence of characteristic zones of system weakening around the defect area. In a two-layer system, there is an increase in internal stresses and strains around the crack, as well as a decrease in the overall strength (stability) of the system. In conclusion, the influence of internal defects of asphalt concrete coatings on the process of formation of "reflected" cracks were identified.

Key words: highway, reflected cracks, operational state, coating quality, defects, strength assessment, stress-strain state

\section{INTRODUCTION}

Roads are one of the main factors in the development of the region and the country as a whole. The social and economic development of the Far Eastern Federal District is associated with the development of a vast territory, thousands of kilometers away from large industrial centers of Russia, and is determined by the condition and efficiency of the transport system [1-4].

The experience of designing and building roads in the south of the Far East has shown that the actual inter-maintenance period of roads is much less than generally accepted in standards. The problem of extending the inter-maintenance period and improving the performance of highways does not have an unambiguous solution [5-7].

According to the decree of the Government of the Russian Federation of May 30, 2017 "On the standards of financial costs and the Rules of the calculation of the federal budget for overhaul, repair and maintenance of federal highways", the inter-maintenance period for the federal highways of the I-IV categories has been increased to 12 years, and the overhaul period - to 24 years.

The service life of many pavements is less than 10 years, while according to the requirements of regulatory documents, it should be 24 years. In addition, the insufficient funds allocated for the repair and maintenance of roads leads to the unrepaired condition of $30-35 \%$ of the existing road network [8-10].

The road is exposed to constant unfavorable atmospheric and natural-climatic effects during its service life: uneven temperature of operation, periodic moistening by surface and ground waters, deep seasonal freezing and uneven thawing of structural layers of road pavement. All these effects lead to the destabilization of the system «road pavement - subgrade», i.e. to a change in the water-thermal condition of the subgrade and a decrease in the strength characteristics of the structural layers of the road pavement [11-13].

Previous studies have established that the strength of subgrade and the general strength of pavement change in proportion to moisture based on the principle: the higher the relative moisture of materials, the lower the strength of the pavement. In general, the deformation modulus of cohesive soils, in accordance with the ODN (Industry Road Codes), varies from 108 to $23 \mathrm{MPa}$ and nonlinearly depends on moisture. Such significant changes in the strength of the soil are unacceptable in the real operating conditions of the pavement and lead to the formation and development of defects in the structure $[3,12,14]$.

The unstable operation of the road base is undoubtedly one of the reasons for the formation of cracks in the monolithic layers of the pavement. Cracks are the most 
common type of defects of the pavement. They are the starting point for the formation of more serious defects and lead to a deterioration in the quality and safety of road traffic.

\section{Research and analysis of the operational condition of roads}

The road and engineering structures on it are constantly exposed to unfavorable atmospheric and natural-climatic effects during their service life: uneven temperature of operation, periodic moistening by surface and ground waters, deep seasonal freezing and uneven thawing of elements and structures. All this leads to the fact that defects (cracks, spalling, potholes, corrosion) are formed in engineering structures. With the timely detection and elimination of defects, the service life of the structure does not change [11, 15, 16]. Unfortunately, at linear construction facilities it is impossible to organize work on continuous monitoring and diagnostics of such elements as road pavement, culverts (reinforced concrete and metal), elements of bridge crossings, guardrails, which leads to the formation and untimely elimination of defects. It must be said that this study does not consider technologies for the repair of metal structures. The main emphasis of the work is on the study of the processes of formation, development and elimination of defects in materials based on organic and inorganic binders used in the practice of road construction.

It is necessary to carry out work on reconstruction of the road with a significant accumulation of defects and deformations. Currently, the most commonly used method of local road repair is patching, when the top layer of the pavement is removed by a milling machine and a new pavement layer is laid in its place. It is recommended to use hot-mix asphalt for repairs, and cold-mix asphalt is used only in those areas where it is impossible to deliver hot mixes. In addition, it is recommended to use recycled asphalt mixtures to reduce the cost of work and the rational use of road building materials [17-20].

The technological sequence of works during the repair of the pavement includes the following operations:

1. cleaning the road surface from moisture, dirt and dust;

2. marking the boundaries of repair work with straight lines along and across the centre line of the road; cutting out the pavement in the place of patching;

3. cleaning the bottom and walls of the repair site from small pieces of asphalt, chips, dirt, moisture and dust;

4. treatment of the bottom and walls with a thin layer of bitumen or bitumen emulsion;

5. road surfacing with asphalt concrete mixtures.

The boundaries of the work are marked with a marker or cut with floor saw, after which a road milling machine (for example, Wirtgen $1000 \mathrm{C}$ ) removes the old pavement to a depth of $5-7 \mathrm{~cm}$.

The asphalt concrete mixture is laid manually or using small-sized asphalt pavers. When laying the mixture by hand, the planning and leveling of the site is also done manually. After laying and leveling the mixture, the mixture is compacted with vibrating tampers and rollers. It should be noted that manual laying and leveling of the mixture reduces the quality of the repaired area and, if possible, should be abandoned (Fig. 1 and Fig. 2)

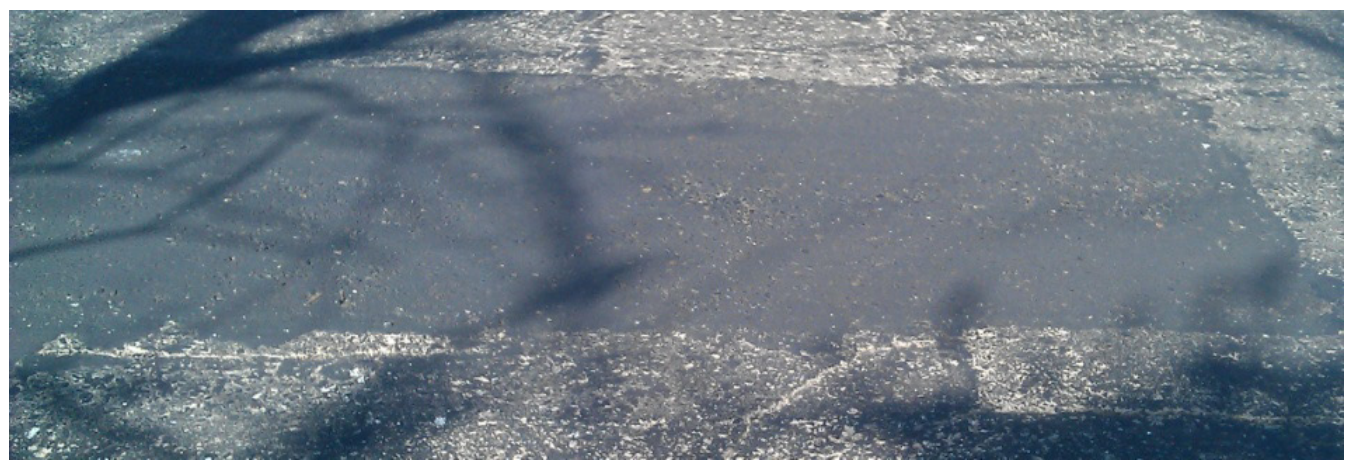

Figure 1: Section of the newly repaired pavement by cold milling in the Khabarovsk Krai

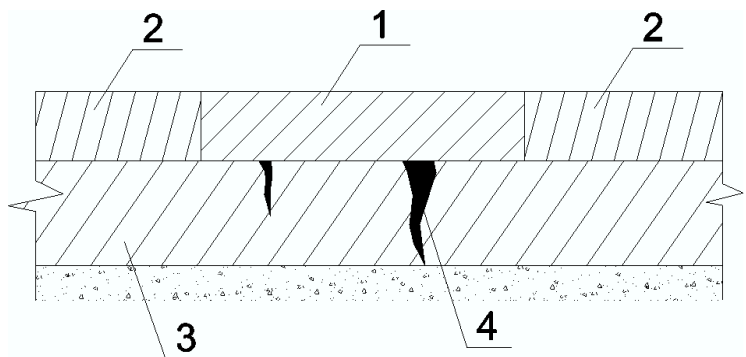

1 - new pavement; 2 - old pavement; 3 - base with defects; 4 - crack filled with bitumen or bitumen mastic Figure 2: Condition of the pavement after patching 
The repair of the road pavement, carried out in compliance with all the requirements and norms of the repair work, allows to ensure the standard work of the repaired section within 3-4 years, and in some cases the warranty is given for 5 years. However, the studies of the operational reliability of road pavements were carried out only for the European part of the country, Europe and the southern territories of the United States, where the climate is milder and there are no large temperature differences [14, 18, 21].

The analysis of statistical data on determining the rate of crack formation on a newly repaired pavement showed that "reflective" cracks appear on the pavement in the period from 1 to 6 months, and the intensity of crack formation depends on the intensity of the traffic and climatic conditions [15].

Defects such as cracks, spalling, potholes, spading and corrosion are eliminated nominally either by sealing the defect with a new material with similar properties, or by physical destruction of a part of the structure followed by filling with a similar material. Only the surface, but not the internal integrity of the structure is restored by eliminating the defect in any way. Small holes or cracks remain inside a structural element (for example, a reinforced concrete beam of a bridge span or an asphalt concrete pavement), which are "reflected" on the surface over time, under the influence of the factors mentioned above. The mechanism of development of "reflective" defects has been studied by domestic and foreign specialists over the past $15-20$ years. It is generally accepted that materials based on cement binder are more subject to the process of formation of reflective cracks due to the rigidity of their internal structure $[14,16,20]$.

Most of the studies on reflective cracks are devoted to the study of physical and chemical processes and the assessment of the stress-strain state of concrete products and materials based on inorganic binders, but this process has not yet been fully studied, let alone materials based on organic binders. In case of untimely or incomplete elimination of defects in the road structure after repair, the reflective cracks appear on the pavement with catastrophic speed. Materials based on organic binder are more plastic, therefore, the bonds between particles are more fragile and cracks develop faster in them.

\section{Physical modelling of "reflective" cracks}

It is generally accepted that cracks in the lower layer of the pavement do not affect the general strength of the pavement structure, since the crack space is filled with a homogeneous material that provides a strong interconnection of asphalt concrete particles with each other. In addition, the value of tension stresses in the upper layers of the pavement is low, which should also not lead to the development of cracks.

The formation of reflective cracks on pavement is a process that occurs in several stages, in which a large number of variable factors are involved. In this regard, the modeling of reflective cracks in the laboratory is a complex, non-trivial scientific task. The methodology proposed by the authors is going through the stages of approbation and accumulation of statistical data.

The samples of a two-layer asphalt concrete pavement with an artificial crack in the bottom layer were tested in the center for building materials of the Pacific State University to test the hypothesis that the defects of pavement base, among others, affect the compression strength of the structure (the main effect of the transport load) [22, 23].

For the production of samples, an asphalt concrete mixture was used, which is most widely used for the construction of pavements in the region: fine-grained asphalt concrete mixture of type $B$, grade I on bitumen with penetration boundaries of 90-130. The mixture was made in an asphalt plant, reheated in the laboratory and molded. The mixture was molded in the temperature range of $140-150^{\circ} \mathrm{C}$ by pressing in steel cylinder molds under a load of $40 \mathrm{MPa}$.

The result of designing the composition of asphalt concrete is shown in Table 1.

According to the experiment plan, 4 series of samples were made, 6 samples in each series: three series of samples with a crack, and one check series without a crack. Samples of cylinder shape with a height of $10 \mathrm{~cm}$ and diameter of $10 \mathrm{~cm}$. When molding, the mixture was laid in two layers with a thickness of $6 \mathrm{~cm}$ and $4 \mathrm{~cm}$ after compaction. The plate of extruded polystyrene foam was placed in the lower layer of the sample to model a crack in the structure of the material, filled with a polymer substance without a frame made of mineral filler. The selected material had sufficient rigidity and temperature resistance (the melting temperature of extruded polystyrene foam is $+270^{\circ} \mathrm{C}$, the temperature of asphalt concrete laying is in the range of $140-150^{\circ} \mathrm{C}$ ) to model cracks in a given direction and with a required depth of $2 \mathrm{~cm}, 3 \mathrm{~cm}$ and $4 \mathrm{~cm}$ (Fig. 3). At the same time, the strength properties of extruded polystyrene foam did not make it possible to create a reinforcing element that would impart additional rigidity to the asphalt concrete sample. The porous structure of extruded polystyrene foam, compacted during the molding of the sample under a load of $40 \mathrm{MPa}$, created an element in the structure of asphalt concrete, similar to a crack filled with polymer-bitumen mastic. The samples were molded in accordance with GOST 12801-98 (National State Standard) [22, 24].

After the required period for cooling, hardening and strength gain, the samples were tested under compression in the compression testing machine IP 6083-500-0 (Fig. 4). Before testing, the samples were not subjected to additional thermostating; the test was carried out at a temperature of $20^{\circ} \mathrm{C}$ in the laboratory. The test results are presented in Table 2.

The crack structure was also modeled using 2 and $4 \mathrm{~cm}$ thick fiberboards. Modeling was carried out in a similar way. The results showed that this material is not suitable 
Table 1. Particle-size distribution of aggregate

\begin{tabular}{|c|c|c|c|c|c|c|c|c|c|c|c|}
\hline \multirow{3}{*}{ Name of materials } & \multirow{3}{*}{$\begin{array}{c}\text { True } \\
\text { density, } \\
\mathrm{g} / \mathrm{cm}^{3}\end{array}$} & \multicolumn{10}{|c|}{ Particle-size distribution (passed through a sieve, \%) } \\
\hline & & 20 & 15 & 10 & 5 & 2,5 & 1,25 & 0,63 & 0,315 & 0,16 & 0,071 \\
\hline & & \multicolumn{10}{|c|}{ Initial data } \\
\hline $\begin{array}{l}\text { Crushed stone fr. } 5-20 \\
\text { mm, Korfovsky quarry }\end{array}$ & 2,71 & 97,4 & 73,12 & 35,71 & 4,71 & 2,11 & 1,74 & 0 & 0 & 0 & 0 \\
\hline $\begin{array}{c}\text { Stone dust, Korfovsky } \\
\text { quarry }\end{array}$ & 2,71 & 100 & 100 & 100 & 98,15 & 81,10 & 70,12 & 55,27 & 41,33 & 29,47 & 14,02 \\
\hline $\begin{array}{c}\text { Natural sand, } \\
\text { Krasnorechensky quarry }\end{array}$ & 2,65 & 100 & 100 & 97,36 & 93,52 & 86,40 & 79,00 & 66,57 & 43,58 & 6,93 & 0,64 \\
\hline \multirow[t]{2}{*}{$\begin{array}{c}\text { Mineral filler powder, } \\
\text { Londoko quarry }\end{array}$} & 2,70 & 100 & 100 & 100 & 100 & 100 & 100 & 100 & 98,89 & 95,81 & 75,59 \\
\hline & $\%$ & \multicolumn{10}{|c|}{ Potential composition } \\
\hline $\begin{array}{l}\text { Crushed stone fr. } 5-20 \\
\text { mm, Korfovsky quarry }\end{array}$ & 45 & 43,83 & 32,90 & 16,07 & 2,12 & 0,95 & 0,78 & 0,00 & 0,00 & 0,00 & 0,00 \\
\hline $\begin{array}{c}\text { Stone dust, Korfovsky } \\
\text { quarry }\end{array}$ & 27 & 27,00 & 27,00 & 27,00 & 26,50 & 21,90 & 18,93 & 14,92 & 11,16 & 7,96 & 3,79 \\
\hline $\begin{array}{c}\text { Natural sand, } \\
\text { Krasnorechensky quarry }\end{array}$ & 20 & 20,00 & 20,00 & 19,47 & 18,70 & 17,28 & 15,80 & 13,31 & 8,72 & 1,39 & 0,13 \\
\hline $\begin{array}{l}\text { Mineral filler powder, } \\
\text { Londoko quarry }\end{array}$ & 8 & 8,00 & 8,00 & 8,00 & 8,00 & 8,00 & 8,00 & 8,00 & 7,91 & 7,66 & 6,05 \\
\hline Total: & 100 & 98,83 & 87,90 & 70,54 & 55,32 & 48,13 & 43,51 & 36,23 & 27,79 & 17,01 & 9,97 \\
\hline \multirow{2}{*}{\multicolumn{2}{|c|}{$\begin{array}{l}\text { Recommended limits according } \\
\text { to GOST 9128-2013, type B, gap } \\
\text { grading }\end{array}$}} & 90 & 80 & 70 & 50 & 38 & 28 & 20 & 14 & 10 & 6 \\
\hline & & 100 & 100 & 100 & 60 & 60 & 60 & 60 & 34 & 20 & 12 \\
\hline
\end{tabular}

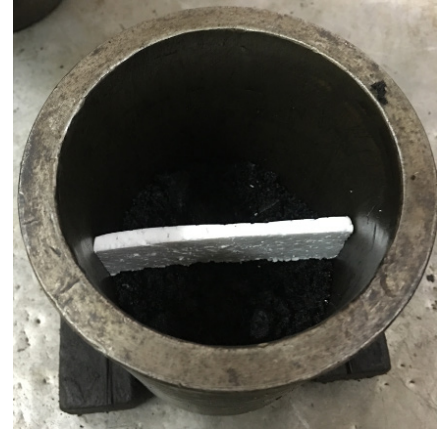

(a)

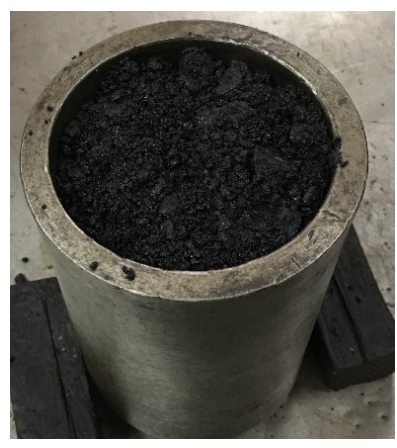

(b)

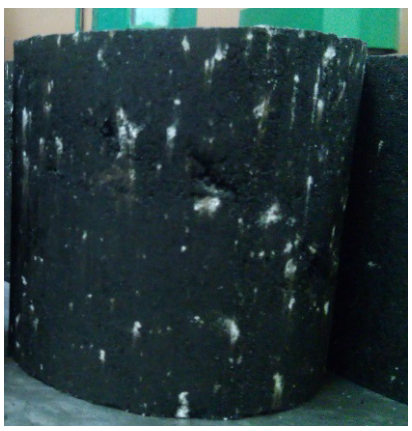

(c) a-laying of the crack; b-sample filled with asphalt concrete; c-two-layer sample

Figure 3: Modeling of crack in the sample
Table 2: Compression strength, $k N$

\begin{tabular}{|c|c|c|c|c|}
\hline \multirow{2}{*}{ Sample No. } & \multicolumn{4}{|c|}{$\begin{array}{c}\text { Compression strength of the sample, } \\
\mathrm{kN}, \text { at the corresponding crack depth }\end{array}$} \\
\cline { 2 - 5 } & $2 \mathrm{~cm}$ & $3 \mathrm{~cm}$ & $4 \mathrm{~cm}$ & check $(0 \mathrm{~cm})$ \\
\hline 1 & 36,49 & 36,71 & 38,60 & 42,29 \\
\hline 2 & 33,31 & 38,07 & 35,57 & 43,46 \\
\hline 3 & 42,64 & 30,82 & 28,87 & 33,20 \\
\hline 4 & 33,55 & 35,35 & 28,93 & 38,60 \\
\hline 5 & 43,22 & 32,00 & 27,80 & 35,89 \\
\hline 6 & 31,19 & 30,05 & 40,17 & 42,91 \\
\hline Average & 36,73 & 33,83 & 33,32 & 39,39 \\
\hline y=ax+b & 36,22 & 34,61 & 32,99 & 39,45 \\
\hline
\end{tabular}

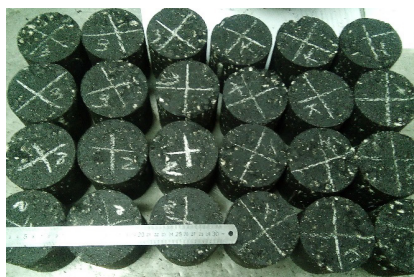

(a)

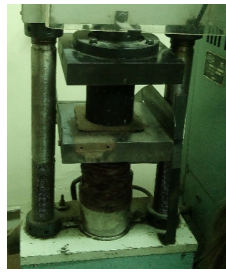

(b) a - sample size; $b$ - test of the sample in the compression testing machine IP 6083-500-0 (ИП 6083-500-0)

Figure 4: Sample size and sample testing 
for crack modeling. However, it has been found that this material is suitable for asphalt concrete reinforcing, since it increases the compression strength by about 10-15\%.

The test results were processed in the STATISTICA software package and, using the least squares method, the empirical dependence of the compression strength on the presence (absence) of a crack in the base and its depth was determined. The dependence is determined by the empirical equation:

$y=A x+b$

where $x$ is crack depth, $\mathrm{mm}$; $A$ is empirical coefficient, $A=-1.614 ; B$ is empirical coefficient, $B=39.452$.

\section{MATHEMATICAL MODELLING}

The GenIDE32 software product was used to solve the task of assessing the performance of a two-layer asphalt concrete pavement with internal deformations.

The GenIDE32 software package is designed to solve applied problems of geomechanics in construction. Its purpose is to calculate, analyze and assess the stressstrain state of elements of the engineering structures and the geological environment within the framework of the model of the system «structure - geologic environment» on the effect of body forces (gravity, filtration, temperature, seismicity) and surface forces.

The solution of static problems of the linear theory of elasticity is carried out on the basis of the numerical solution of the equations of the linear theory of elasticity by the finite element method [25-28].

The equilibrium equations for a homogeneous, isotropic and ponderable body are as follows

$\sigma_{i j, J}+F_{i}=0$

where $\sigma_{i j, J}$ are the partial derivatives of the stress tensor and $\mathrm{Fi}$ are the body forces in the coordinate system $\mathrm{i}, \mathrm{j}=\mathrm{x}, \mathrm{y}, \mathrm{z}$.

The relative strains are considered small, and the components of relative strain tensor are determined by the Cauchy equations - geometric equations

$\varepsilon_{i j}=0.5\left(u_{i, j}+u_{j, i}\right)$

where $u_{i, j}, u_{j, i}$ are the partial derivatives of the components of the displacement vector in the used coordinate system.

The conditions of the connection between the components of the stress tensor and the relative strain tensor (physical equations) have the following form

$$
\sigma_{i j}=E_{i j k l} \varepsilon_{i j}
$$

where $E_{i j k l}$ are the components of the symmetric elastic tensor, namely

$E_{i j k l}=E_{j i k l}=E_{j i l k}=E_{i j k k}$

Strain compatibility equation (Navier equations)

$E i_{j k l} u_{j, k k}+E_{i j k l} u_{j, k i}+F_{i}=0$

The boundary conditions are written in the form

$u_{i}=u_{i} n_{i} o n S_{u}$
$F_{i}=\sigma_{i j} n_{i} o n S_{f}$

where $n_{i}, n_{i}$ are direction cosines on the boundaries $S_{u}$ and $S_{f} ; u_{i}, F_{i}$ are vectors of displacements and forces at the same boundaries, respectively.

The principle of virtual displacements (Lagrange), on which the physical interpretation of the finite element method is based, states that in an equilibrium state with arbitrarily small displacements, the total work of internal forces is equal to the total virtual work of external forces

$\int_{V} \delta \varepsilon^{T} \sigma d V=\int_{V} \delta u^{T} p d V=\int_{S} \delta u^{T} q d S=\int_{L} \delta u^{T} f_{L} d L$

where $\delta \varepsilon$ are the variations of the relative strain tensor; $\sigma$ is the internal stress tensor; $\delta u$ are the variations of the vector of virtual displacements; $p, q, f L$ are volume, surface and point external loads acting on the system (body).

Minimizing equation (9) brings it to the form of the main equation of the finite element method written in matrix form $[K]\{u\}=\{F\}$

where $[K]$ is the global stiffness matrix of the system; $\{u\}$ is the global displacement vector; $\{F\}$ is the global force vector.

The standard expression for calculating the stiffness matrix of any finite elements has the following form

$[K]=\int_{V}[B]^{T}[D][B] d V$

where $[B]$ is the matrix of shape functions derivatives; $[D]$ is the elasticity matrix; $[B]^{T}$ is the transposed matrix of shape functions derivatives; $V$ is the volume over which the integration is performed.

The elasticity (material properties) matrix for the plane problem of the theory of linear elasticity is written in the form

$[D]=\frac{E}{(1+v)\left(1-v_{1}\right)}\left[\begin{array}{ccc}1 & v_{1} & 0 \\ v_{1} & 1 & 0 \\ 0 & 0 & \left(1-v_{1}\right) / 2\end{array}\right]$

where $E$ is the modulus of deformation (elasticity); $v$ is the Poisson's ratio, $\mathrm{v} 1=\mathrm{v}$ for a plane stress state; $\mathrm{v} 1=\mathrm{v}(1-\mathrm{v})$ for plane strain.

The elasticity matrices for the plane elasticity problem involve the use of the following vectors of relative strain and stress in physical equations

$\{\varepsilon\}=\left\{\varepsilon_{x x} \varepsilon_{y y} \varepsilon_{x y}\right\}^{T}$

$\{\sigma\}=\left\{\sigma_{x x} \sigma_{y y} \sigma_{x y}\right\}^{T}$

Principal stresses and relative strains are calculated using the formulas of the theory of stresses and strains in continum mechanics.

Average stresses and average relative strains are calculated by the formulas

$\sigma_{m}=\left(\sigma_{1}+\sigma_{2}+\sigma_{3}\right) / 3$

$\varepsilon_{m}=\left(\varepsilon_{1}+\varepsilon_{2}+\varepsilon_{3}\right) / 3$

where $\sigma_{1}, \sigma_{2}, \sigma_{3}$ and $\varepsilon_{1}, \varepsilon_{2}, \varepsilon_{3}$ are the components of principal stresses and relative strains. 


\section{RESULT}

In the simulation model, the crack depth in the bottom layer of a two-layer asphalt concrete structure is $3 \mathrm{~cm}$ with a width of $4 \mathrm{~mm}$. A crack in the model is represented by a weakened layer of asphalt concrete: the modulus of elasticity of the upper layer is $2400 \mathrm{MPa}$, the lower layer is $1400 \mathrm{MPa}$, and the crack is $800 \mathrm{MPa}$. The overall dimensions of the model are $19 \times 8 \mathrm{~cm}$.

The stress-strain state was assessed using the GenIDE32 program. The vertical stress tensors and total stresses in the primary model $(A)$ and the model simulating a crack (B) are shown in Fig. 5 and Fig. 6.

The analysis of the simulation results (Fig. 5 and Fig. 6 ) showed that the vertical stress tensors $\sigma_{y y}$ and total stresses $\sigma$ in the simulation models change insignificantly. In the crack zone, there are practically no vertical

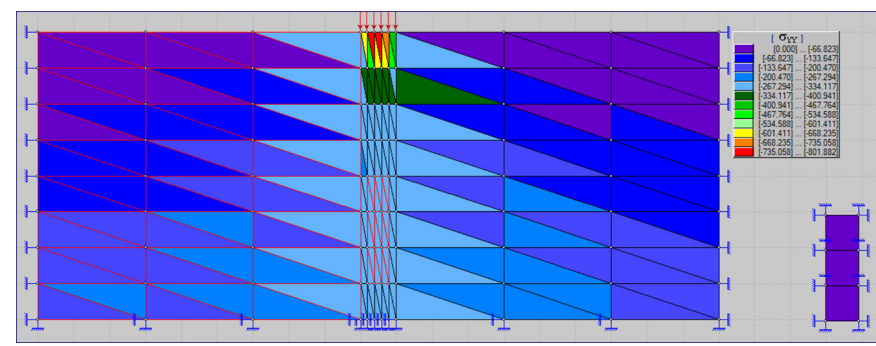

(a)

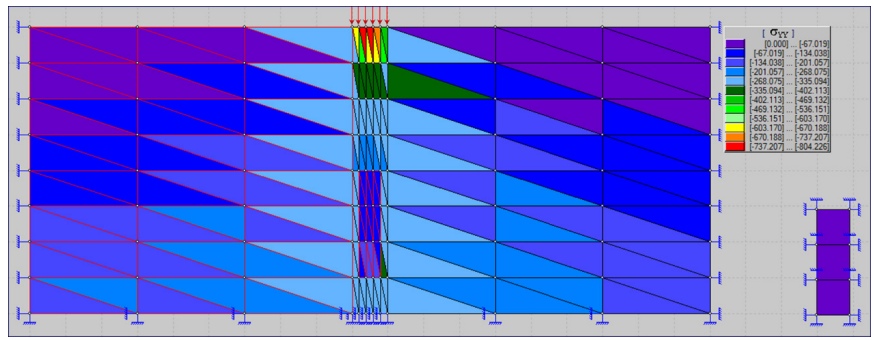

(b)

Figure 5: Vertical stress tensors oyy

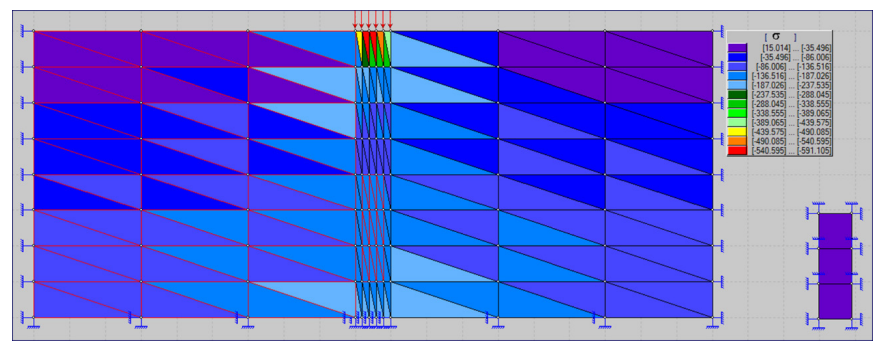

(a)

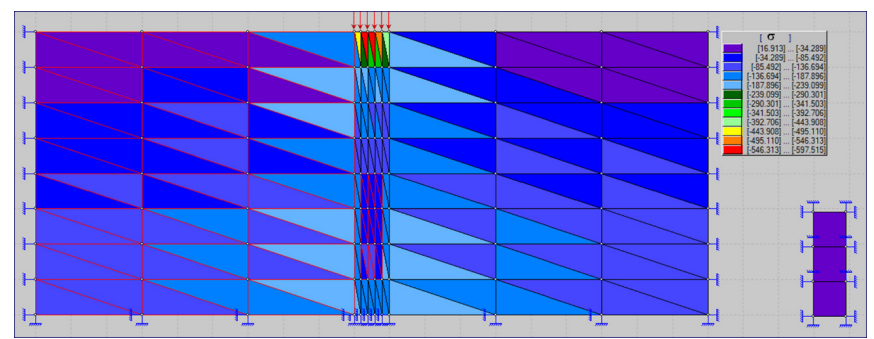

(b)

Figure 6: Total stresses of the system $\sigma$ stress tensors $\sigma_{y y}$, and the total changes in the vertical stress tensors are no more than $0.5 \%$, and these changes can be neglected.

The vertical strain tensors and total strains in the primary model (A) and the model simulating a crack (B) are shown in Fig. 7 and Fig. 8.

An additional assessment of the strength (stability) coefficient of the primary model (A) and the model simulating a crack (B) showed that the presence (absence) of internal structural defects (cracks) leads to a slight (up to $5 \%$ ) overall decrease in the strength of the structure (Fig. 9). This is primarily due to the fact that the crack is a micro-weakening of the structure and after filling with bitumen or mastic, the internal bonds in the material are restored. Nevertheless, as a result of prolonged repeated application of the load, the destruction of the material begins precisely in the zone of weakening, since neither

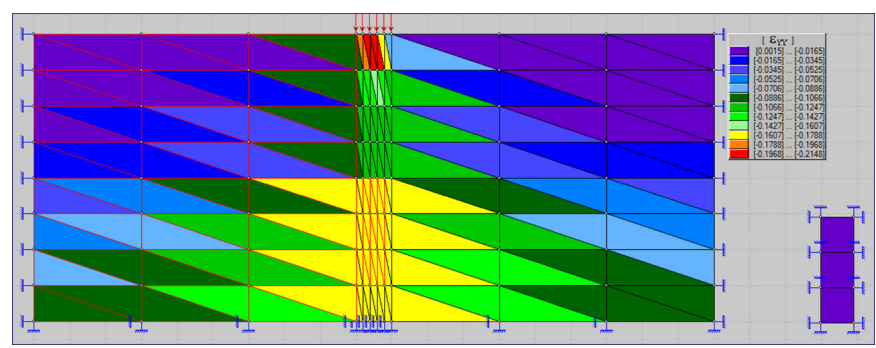

(a)

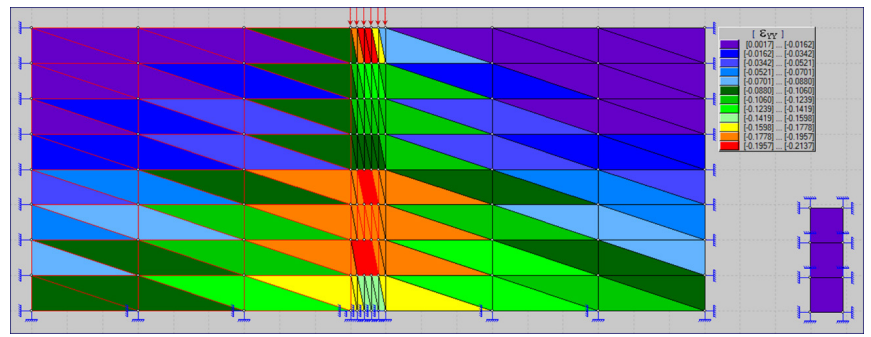

(b)

Figure 7: Vertical strain tensors عyy

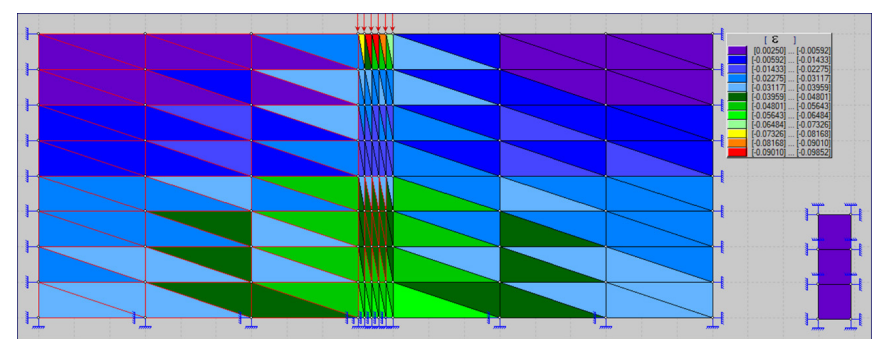

(a)

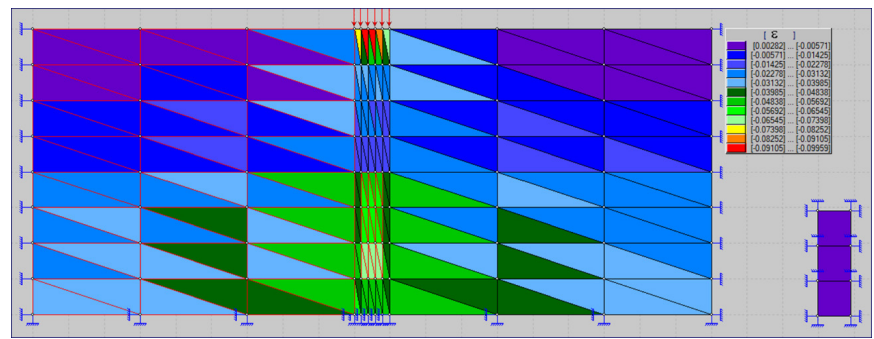

(b)

Figure 8: Total strains of the system $\varepsilon$ 


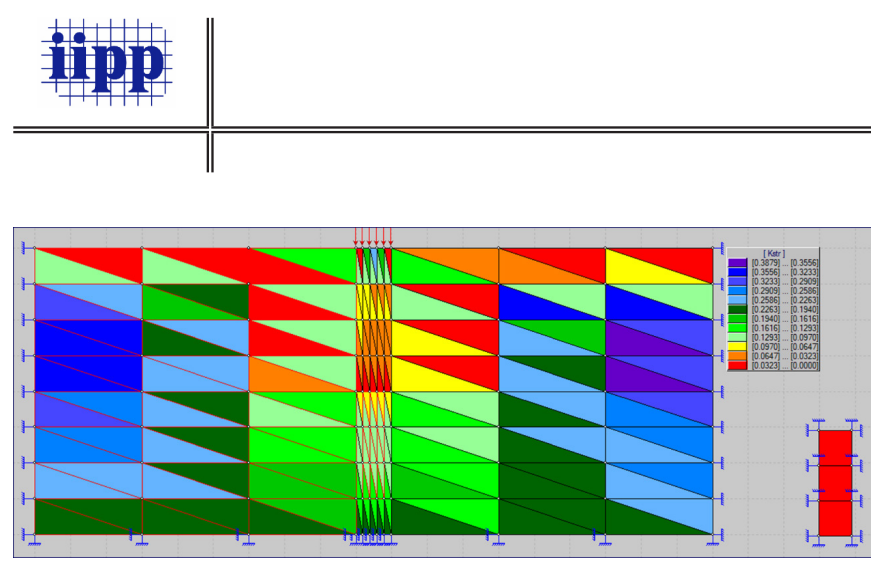

(a)

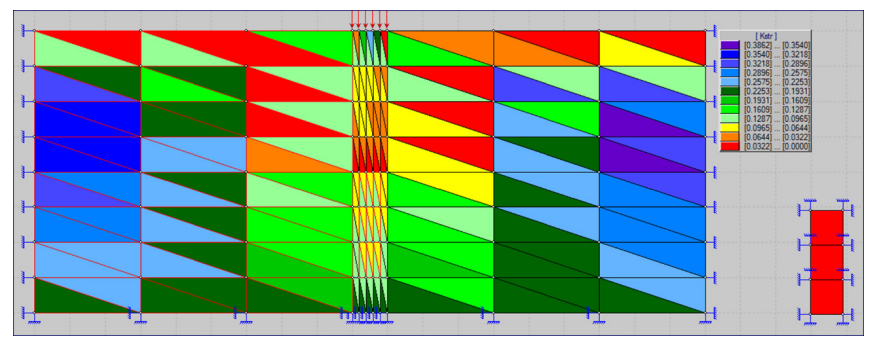

(b)

Figure 9: Strength (stability) coefficient of the system Kstr (developed by the author)

bitumen nor mastic provide such strong bonds as the conglomerate structure of asphalt concrete.

Also, the analysis of the strength (stability) coefficient of the system Kstr shows that small prototypes of a two-layer asphalt concrete structure (laboratory cylinders 10x10 $\mathrm{cm}$ and a mathematical model $19 \times 8 \mathrm{~cm}$ ) do not have sufficient strength to resist the effect of the calculated transport load, but they allow us to say with the necessary level of reliability that the material with internal defects has less strength and is subject to accelerated destruction precisely in the zone of weakening of the structure.

\section{DISCUSSION}

The results of the study correlate with the results of studies by Russian and foreign authors and do not contradict the existing theories and models for assessing the strength and stability of road pavements $[12,16,18]$.

Obtaining the results is of great practical importance and can be used in the construction and reconstruction of highways in any natural and climatic conditions. In addition, the results of the study can be used to improve the subgrade-pavement system and develop new ways to strengthen the base of the pavement.

\section{CONCLUSION}

As a result of the studies performed, it can be said unambiguously that internal defects in a two-layer structure lead to a decrease in the strength of the system. In addition, the following conclusions can be drawn:

- Physical and mathematical modeling of the operation of a two-layer asphalt concrete structure with a crack and without a crack give approximately the same results, the distribution of the principal and vertical stresses is even and the sample is destroyed correctly under the action of a vertical load.
- Modeling and assessment of vertical strains in the structure show that an increase in strains occurs only in the zone of weakening of the structure. Cyclic repetition of loads leads to the accumulation of internal stresses and fatigue deformations, as a result of which a "reflective" crack or more significant structural defect forms on the surface.

- The rate of formation of "reflective" defects of pavement could not be determined during physical modeling, since for this it is necessary to subject the structure to repetitive short-term effect of the design load.

- Mathematical modeling of repetitive loading of a structure shows the rate of accumulation of internal stresses and strains, and speaks only of the number of applications of the design load necessary for the accumulation of the maximum allowable stressstrain state of the structure.

\section{ACKNOWLEDGEMENT}

The studies was supported by the grant of the President of the Russian Federation, contract No. 075-15-2020286 (internal number MK-511.2020.8).

\section{REFERENCES}

1. Yarmolinsky V.A., Lopashuk A.V. (2012) Methods to increase reliability in the operation of road constructions, road network in the Far East. Transport construction, No 3, Pp. 6-9. Retrieved from https:// elibrary.ru/item.asp?id=18914399

2. Kamenchukov A.V., Yarmolinsky V.A., Krivko E.V. (2016) Influence of initial information on the quality of design, construction and repair of highways, 2016, 180 p. Retrieved from https://elibrary.ru/item. asp? $\mathrm{id}=28891034$

3. Kamenchukov A. (2019). Application graphoanalytical method for assessing the change in the speed of movement of vehicles means after repair of highways. Journal of Applied Engineering Science, 2019, vol. 17, br. 4, str. 473-481. doi:10.5937/jaes 17-20088

4. Belutsky I Y, Alekseeva I D (2020) Analytical Solutions for Taking into Account Composite Action of Reinforcement and Concrete in the Evaluation of Stresses in the Principal Planes of Girder Web Plates with Prestressed Reinforcement. IOP Conference Series: Materials Science and Engineering, 2020, 753(3), 042074 Retrieved from https://doi. org/10.1088/1757-899X/753/4/042074

5. Davis K.L. (2001) The Rocky Road To Translation In Spinal Cord Repair. Automotive News, Vol. 75, No. 5915, P. 36. 
6. Radovsky B.S. (2006) The problem of increasing the durability of pavements and methods of its solutions in the US. Internet Laboratories, Inc., USA: Series: Road Construction Equipment, 2006. Pp. 108-119.

7. Lopashuk V.V., Kormilitsyna L.V., Ta Minyan (2014) Standard road structures in the northern provinces of People's Republic of China. Transport construction, No 9, Pp. 16-20. Retrieved from https://elibrary. ru/item.asp?id=22457115

8. Yarmolinsky V.A. (2005) Optimization of the development of the regional road network of the Far Eastern Federal District, Pacific National University Publishing House, 236 p. Retrieved from https://elibrary. ru/item.. asp?id=19774950

9. Yarmolinsky V.A. (2015) Regulation of the water-thermal regime of the highways of the Far East to increase their reliability during operation. Second International Symposium on the problems of the roadbed in cold regions: Proceedings of the Symposium, September 24-26, 2015. Pp. 127-133. Retrieved from https://elibrary.ru/item.asp?id=25378087

10. Yarmolinsky V.A., Lopashuk V.V., Ta Minyan (2015) Increasing of road transport efficiency at international crossings with China. Transport construction, No 3, Pp. 9-12. Retrieved from https://elibrary.ru/item. asp?id=23179752

11. Wise B. (1994) Rising From The Rubble: Los Angeles Repairs Its Roads. American City \& County, Vol. 109, No. 13., Pp. 36 - 43.

12. Goryachev M.G. (2013) The estimation of the reduction degree of cohesive soils elastic modulus as a result of their spring decompression for the forecast of pavement condition. Bulletin of the Moscow Automobile and Road Construction State Technical University (MADI), No. 4(35), Pp. 77-82. Retrieved from https://elibrary.ru/item.asp?id=20681923

13. Goryachev M.G. (2013) Clarification of the design parameters of road pavement loading. Science and Engineering for Highways, No 3, Pp. 14-15. Retrieved from https://elibrary.ru/item.asp?id=20219669

14. Onyango, M., Merabti, S.A., Owino, J., Fomunung, I., Wu, W. (2018) Analysis of cost effective pavement treatment and budget optimization for arterial roads in the city of Chattanooga. Frontiers of Structural and Civil Engineering, 12 (3), pp. 291-299. Retrieved from https://doi.org/10.1007/s11709-017-0419-5

15. Kamenchukov, A., Yarmolinsky, V., \& Pugachev, I. (2018). Evaluation of road repair efficiency in terms of ensuring traffic quality and safety. Paper presented at the Transportation Research Procedia, 36 627633. doi:10.1016/j.trpro.2018.12.142 Retrieved from www.scopus.com
16. Arora, M. K., Patel, M. R., \& Titiksh, A. (2021). Study of pavement unevenness using sensor-based smartphone software. Lecture Notes in Civil Engineering, 77, pp 879-898 Retrieved from https://doi. org/10.1007/978-981-15-5195-6_64

17. Kamenchukov A.V., Yarmolinsky V.A. (2013) Improving the efficiency of road repair taking into account their operational condition, Pacific National University Publishing House, 147 p. Retrieved from https:// elibrary.ru/item. .asp? id=28970780

18. Kim, S., Yeo, H. (2017) Evaluating link criticality of road network based on the concept of macroscopic fundamental diagram. Transportmetrica A: Transport Science, 13 (2), pp. 162-193. Retrieved from https:// doi.org/10.1080/23249935.2016.1231231

19. Zhigulinsky V.I., Galygin O.V. (2014) Repairing automobile roads with the usage of modern technologies and materials. Bulletin of Science and Education Development, No 2, Pp. 125-128. Retrieved from https://elibrary.ru/item.asp?id=21474994

20. Ushakov, V.V., Yarmolinsky, V.A., Dobrov, E.M., Goryachev, M.G., Lugov, S.V. (2017) Revision of descriptions and calculated properties of road bed soils and asphalt concrete materials upon designing of highway pavements in terms of criteria of residual deformations and fatigue cracking of asphalt concretes. International Journal of Civil Engineering and Technology, 8 (9), pp. 10741083. Retrieved from https://www.scopus.com/ record/display.uri?eid=2-s2.0-85030679794\&origin $=$ resultslist \&sort $=$ plfdt - f \&listld $=$ myList \&s $r c=s \& i m p=t \& s i d=b 155 a f 5307 b 014 a 736 e-$ 721 ae 5 e 444 af $1 \&$ sot $=m|\& s d t=m| \& s \mid=0 \&$ relpos$=0 \&$ citeCnt $=2 \&$ searchTerm $=$

21. Khan, T.U., Norton, S.T., Keegan, K., Gould, J.S., Jacques, C.D. (2017) Use of multiple non-destructive evaluation approaches in Connecticut to establish accurate joint repair and replacement estimates for composite pavement rehabilitation. Airfield and Highway Pavements 2017: Design, Construction, Evaluation, and Management of Pavements - Proceedings of the International Conference on Highway Pavements and Airfield Technology 2017, 2017-August, pp. 201-208. Retrieved from https://www.scopus.com/record/display. uri?eid=2-s2.0-85048974791\&origin=resultslist

22. Arulrajah, A., Baghban, H., Narsilio, G. A., Horpibulsuk, S., \& Leong, M. (2020). Discrete element analysis of recycled concrete aggregate responses during repeated load triaxial testing. Transportation Geotechnics, 23 doi:10.1016/j.trgeo.2020.100356 
23. Kamenchukov A.V., Ukrainskiy I.S. (2019) Modeling of cracks in asphalt concrete pavement. Modern problems and directions of development of the automobile and road complex in the Russian Federation // collection of works of the All-Russian (National) Scientific and Practical Conference. October 23-25, 2019. Penza: Penza State University of Architecture and Construction, 2019. Pp. 68-70

24. Mandloi, S., Kumrawat, S., \& Deulkar, V. (2021). Comprehensive study on foamed bitumen doi:10.1007/978-981-15-5195-6_66 Retrieved from www.scopus.com

25. Grishm, I., Kayumov, R., \& Ivanov, G. (2020). Asphalt concrete pavements of bridges under thermal stress. Paper presented at the IOP Conference Series: Materials Science and Engineering, 890(1) doi:10.1088/1757-899X/890/1/012032 Retrieved from www.scopus.com
26. Leonardi, G., Bosco, D. L., Palamara, R., \& Suraci, F. (2020). Finite element analysis of geogrid-stabilized unpaved roads. Sustainability (Switzerland), 12(5) doi:10.3390/su12051929

27. Lu, G., Wang, H., Torzs, T., Liu, P., Zhang, Y., Wang, D., ... Grabe, J. (2020). In-situ and numerical investigation on the dynamic response of unbounded granular material in permeable pavement. Transportation Geotechnics, 25 doi:10.1016/j.trgeo.2020.100396

28. Mapa, D. G., Gunaratne, M., Riding, K. A., \& Zayed, A. (2020). Evaluating early-age stresses in jointed plain concrete pavement repair slabs. $\mathrm{ACI}$ Materials Journal, 117(4), 119-132. doi:10.14359/51725780 